\title{
Water Purification by Activation Plasma Technology
}

\author{
Chandan Kumar, Ankit Raj Sinha, Sanjay Prakash, Khushwant Singh, Saurabh Kumar
}

\begin{abstract}
In modern water treatment technologies Water needs to be processed to a level that can be reused in a meaningful way. Plasma production or plasma injection in liquid water provides an opportunity to inject advanced Oxidation processes in water for purification or chemical processing. Such technology can revolutionize Drinking water treatment, as well as current practices of chemical processing by removing physical catalysts. An overview of current water treatment is presented here where Technology, its limitations and the future, may include Plasma-based advanced oxidation method. In plasma Introduction to liquid water produces and attacks a host of reactive species finally mineralize the contaminants in the solution. This interaction takes place at the boundary layer or at the interaction zone is concentrated at the plasma - liquid water interface. There are limitations of traditional plasma injection procedures which include limited throughput capacity, electrode shear and reduced Process Volume. Here the technical limitations of plasma based water reactor will also be discussed.
\end{abstract}

Keywords-New Technology, Waste Water, Organic Compound, Water Pollution, Advance oxidation process, Plasma method, Plasma based Water Reactor

\section{INTRODUCTION}

UN passed a goals proclaiming access of drinking clean water a basic human right to every human being on earth. Freshwater scarcity derived from seasonal weather variations, climate change, and over-development has led to serious consideration for water reuse. Water reuse involves the direct processing of wastewater for either indirect or directly potable water reuse. In either case, advanced water treatment technologies will be required to process the water to the point that it can be reused in a meaningful way. Additionally, there is growing concern regarding micropollutants, such as pharmaceuticals and personal care products, which have been detected in finished drinking water not removed by conventional means. Pollution Reduces water quality and so on Effect of reducing water availability. It can be used for drinking or farming Applications which refers to pollution here, Introduction of harmful contaminants Organic chemicals or microorganisms from human or animal waste into freshwater sources.

Revised Manuscript Received on July 07, 2020

* Correspondence Author

Chandan Kumar*, Assistant Professor, Department of civil engineering, NSIT Bihta, Patna India.

Ankit Raj Sinha, Assistant Professor, Department of civil engineering, NSIT Bihta, Patna India.

Sanjay Prakash, Assistant Professor, Department of civil engineering, NSIT Bihta, Patna India.

Khushwant Singh, Assistant Professor, Department of civil engineering, NSIT Bihta, Patna India.

Saurabh Kumar, Assistant Professor, Department of civil engineering, NSIT Bihta, Patna India.

(c) The Authors. Published by Blue Eyes Intelligence Engineering and Sciences Publication (BEIESP). This is an open access article under the CC BY-NC-ND license (http://creativecommons.org/licenses/by-nc-nd/4.0/)
According to WHO Almost one billion people do not have clean access of Drinking water and estimated 500 Million people die of the disease each year associated with contaminated sources. So for this challenge, one new and emerging technology that could potentially address the removal of micro pollutants in both finished drinking water as well as wastewater for its reuse is plasma-based water purification. Plasma in contact with liquid water generates a host of reactive species that attack and ultimately mineralize contaminants in solution. This technique is achievable because of advancement in water reuse. For reusing now, and reusing of industrial drain is used for water supply, reuse, and power the springs. For such a reusable pathway to be effective, a new development technology is needed for the scrapping of unsafe particles and bringing back the strength of normal water flow.

Conventional water treatment system - For absorbing large-scale waste from water and then reuse for reducing pressure on freshwater reserves and provide potable water after processing. Existing water treatment technology in typical city water treatment plant focuses on filtration and disinfection. Particulates and Pollutants are filtered from the input water flows through the multiple processes in which chemical coagulation agents are added to the water to encourage the formation of larger particulates, which are then removed via sedimentation and subsequent filtration. This water is then disinfected, usually with chlorine, ozone or UV Light. Fig. 1 shows the working of the system of Water treatment plant. In this case, conventional water Treatment refers only to particulates and bacteria in which Industrial and toxins in agriculture-derived wastewater cannot be directly solved by conventional water treatment especially Volatile organic compounds (VOC). These organic compounds can also be concentrated in the air and in the water. Because of this property, VOCs can migrate through Drinking water sources and continuing there. These toxins of particular concern are the main reason for contamination of surface and reservoirs of fresh water resources. These toxins are linked to the host Human health effects range from loss to circulation System for the digestive and nervous systems.

Overall, new technologies and methods of water monitoring It is necessary to address the above mentioned toxins. In addition, Implementation of such new technology Follow a detailed public health and toxicity survey. It can be assumed that pollution levels will one day be brought arbitrarily low; its densities can still be measured with advanced detection methods. 


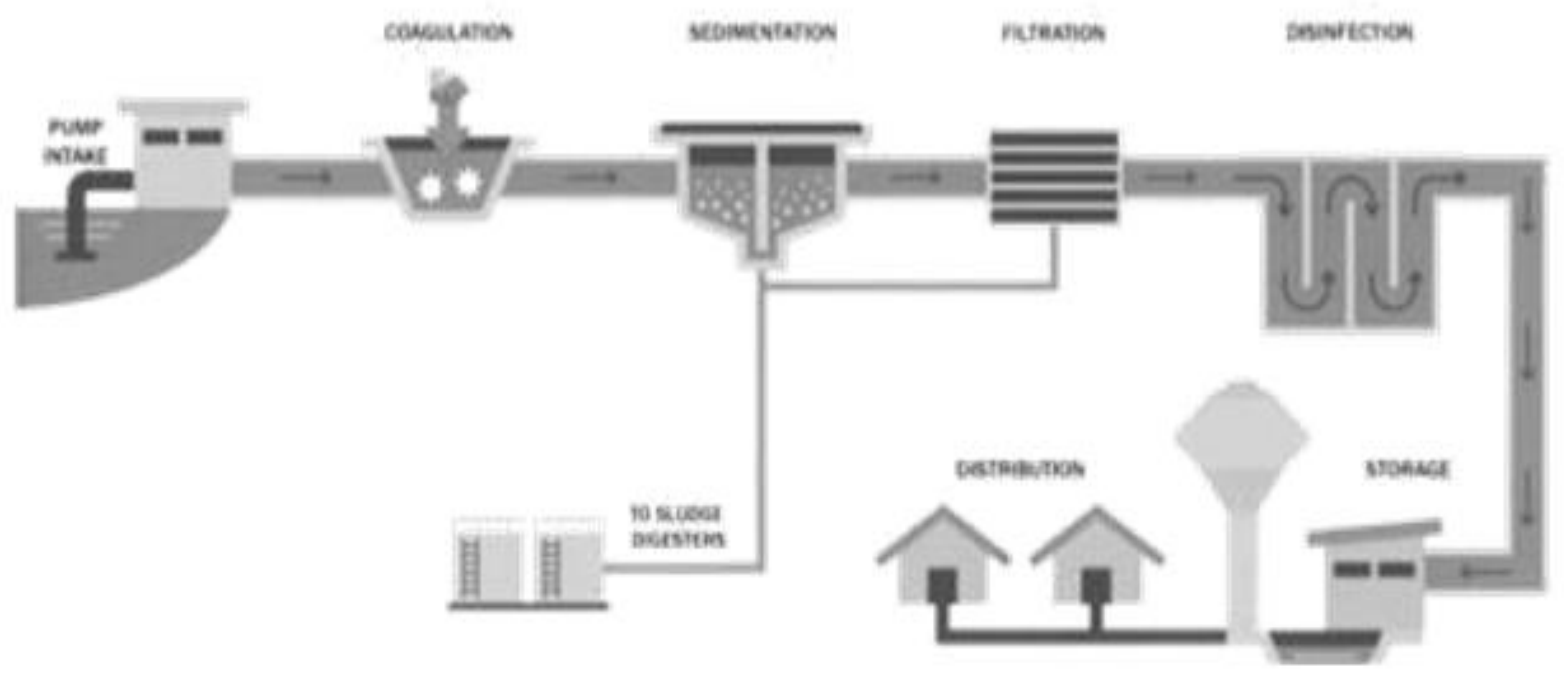

Fig 1- Schematic diagram of conventional water treatment system

\section{II.WATER PURIFICATION}

Ion Exchange Process- is the process where an insoluble substance removes ions of positive or negative charge from an electrolytic solution and releases other ions of the same charge into solution in a chemically equivalent amount. Ion exchange processes involve the use of ion exchange resins. Ion exchange resins are Synthetic copolymers of exchange resins which attach to Functional groups then behave as acids, alkalis or salts. Ion exchange processes are used for removal complete removal of hardness, alkalinity or dissolved solids from Water. The ion exchange process is reversible and therefore resins should be used repeatedly.

Advance oxidation process- Advanced oxidation process have shown a remarkable tendency for water purification and wastewater treatment, containing naturally occurring toxins, organic and inorganic pollutants, pesticides and other pollutants such as nanomatadium or used as pretreatment to convert recalcitrant pollutants into biodegradable compounds that can be treated by conventional biological methods. The performance of AOPs depends on the generation of free radicals, the most being the hydroxyl radical $(-\mathrm{OH})$.

Advanced oxidation process using strong hydroxyls or sulfate radicals as major oxidizing elements was first proposed in 1980 for potential water treatment. Later, AOPs are widely used for the treatment of various types of wastewater because strong oxidants can easily damage organic pollutants and remove certain pollutants from contaminated water.

Since 1990s, the characterization and development of AOPs, has grown and incorporated numerous hydroxyl radical and other ROS production methods. AOPs contain UV/H2O2, UV/O3, and Fenton, photo- plasma, nonthermal radiolysis, sonolysis, photocatalysis and very high oxidation processes. Many AOPs are introduced as a result of sonolysis, radiolysis, pr photolysis. Even sonolysis and radiolysis produce hydroxyl radicals without the involvement of chemical

oxides in water sources, while photochemical methods require catalyst or precursor. For example, the photo-Fenton type processes to produce hydroxyl.

Advanced oxidation strategies and techniques are the most commonly used chemical reactions of oxygen hydrogen radical due to the salinity of modern chemical compounds. Because advanced oxidation processes have the potential to reduce the concentration of naturally occurring pollutants in brine, these are called drain water purification techniques. Oxygen hydrogen radical has a voltage reduction of 2.6 volts due to fluorine $(F)$ in the element. Although radical AOP requires oxygen hydrogen, the timedependent oxidation process processes chemical pathways, resulting in a high reduction potential, which immediately creates oxygen-hydrogen radical or invasive organic compounds. Advanced oxidation methods include activated nitrogen, ultrasound, unusually important water, nuclear oxygen, ultraviolet moderate ozone and peroxide. Ozone cooperates with hydrogen peroxide. Now, half the advance, including every oxide development, is inevitable.

Again, some moderate advances have been added, where two particles of ozone react with per-oxide to produce oxygen hydrogen atoms, which are two numbers. Another creation device is the oxygen hydrogen contribution with per-oxide iron particles, also known as the ffenton reaction. Each oxide breaks down into hydrogen and is filled with iron. The just-formed iron particle allowed the peroxide particles to cooperate to produce additional oxygenhydrogen radicals. The present Ffenton response is explored by a way to break down the material colors in the canal water.a 


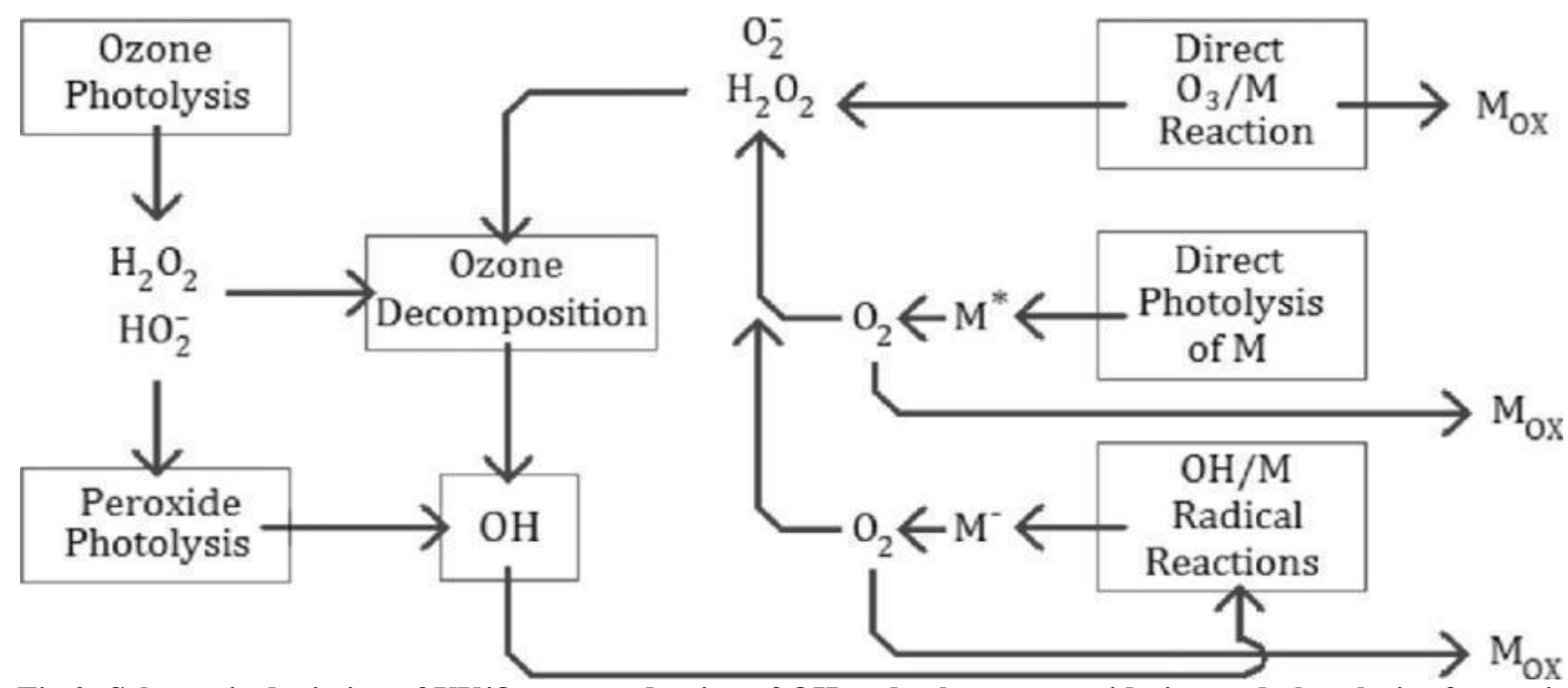

Fig 2- Schematic depiction of UV/Ozone production of $\mathrm{OH}$ and subsequent oxidation and photolysis of organic contaminants

\section{Deterioration of organic contaminants by advanced oxidation processes- As}

mentioned earlier, $\mathrm{OH}$ is a chief oxidizer. AOPs what has been mentioned so far is that $\mathrm{OH}$ produces in high amounts. The $\mathrm{OH}$ Radical mineralization of organic compounds in solution to carbon Dioxide, water and inorganic intermediates, thereby rendering contaminants are harmless.

The decomposition path of organic Contaminants must be caused by two chemical pathways: (i) abstraction; and (ii) addition. In the extraction process, $\mathrm{OH}$ Removes hydrogen from the molecule, thus changing it Molecule into the radical. Chain radical oxidation causes more and more degradation of organic molecule. In an additional process, the Radical aromatic and unsaturated can be added to double bonds and the molecules also produce radicals that eventually degrade by chain oxidations. The radicals produced only react with it $\mathrm{OH}$ but also in solution with oxygen and peroxide. These initial processes lead to decomposition of the contaminant. Undoubtedly, those strategies are fundamental to eliminating microbial inactivation and viral production. Thus, sophisticated oxidation strategies can be thought of as an adjunct to standard disinfection systems that the use of Chlorine. These compounds have been linked to the development of pathogens and tumors with bladder heart disease. The main butcher component for chlorine performance in microorganisms is, in all accounts, using a portable divider or film reactions to inhibit the normal microbial metabolism. Since it usually does not involve the elimination of cell dividers, it is the science of microorganisms and protozoa to work for miles to develop protection from chlorine. Forward movement completes a wide variety of film and cell divider pulverization. The best of the class oxidation forms are the oxidation of bacterial cell membranes that allow chlorine to go into the cell and destroy it in the long run. In general, chlorine has a limited answer to safe microorganisms in water-driven oxidation systems. Because the system is compact, microbial and viral cells cannot develop protection from sophisticated forms of oxidation. Finally, the ability to inactivate microorganisms in a pilot plant requires examining the forms of cutting edge oxidation.

\section{III.PLASMA AND WATER PURIFICATION}

What Is Plasma- Plasma is the state of matter in which ionized gaseous matter becomes highly conductive, causing distant electric and magnetic fields to influence the behavior of the material. Plasma conditions can be compared with other states: solid, liquid and gas. Plasma is an electrically neutral medium of unlimited positive and negative particles (i.e. the total charge of the plasma is approximately zero). Although these cells are infinite, they are not "free" in the sense that they do not experience forces. Moving charged particles creates an electric current inside the magnetic field, and any movement of charged plasma particles affects the fields generated by other charges. It regulates mass behavior with varying degrees of variation.

Why Plasma for Water Purification- The above mentioned physical processes which are leading to $\mathrm{OH}$ formation in water are also generated when plasma is placed in contact with water. Plasma is a source of high electric fields, energetic charged particles, ultrasound, UV light and even shockwaves, which can drive $\mathrm{OH}$ production in solution. It can be induced in wastewater by formation of plasma above the water surface or within the surface of water. In both approaches, the plasma interacts with water at the gas-liquid interface. Reactions at this point lead to expansion of products from interface and air condition, Induces chemical reactivity to the liquid state Plasma. In addition to these $\mathrm{OH}$ production systems, many other reactions, including thermal dissociation which occurs at a higher gas temperature than that 2200K, Electron-Ion Dissociative Recombination, Water Ion Dissociation driven by hydration, interaction with radicals, Metastables and positive-negative ion recombination. Basically, the production efficiency of $\mathrm{OH}$ depends on the electron temperature and the plasma density, work gas composition and temperature, and the excitatory mechanism, which depends on the mechanism by which the plasma is first produced.

Blue Eyes Intelligence Engineering
\& Sciences Publication

(C) Copyright: All rights reserved.

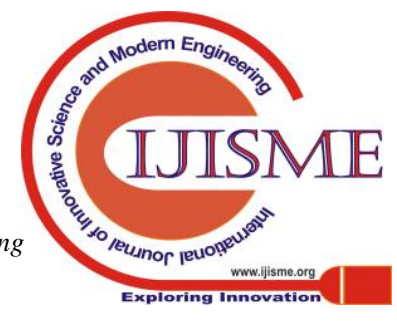


Plasma effect on Germination-Plasma activated water (PAW) has shown a significant impact on germination. This is easy to apply by replacing the traditional sanitizing solutions. PAW has the ability to inhibit the hormones responsible for seed dormancy. Active species of PAW contribute to seed germination enhancement. PAW appears to have a synergistic effect on the disinfection of food while it can also promote seeding growth of seeds. The increase in the nitrate and nitrite ions in the PAW not only serves as an anti-bacterial but also enhances the seed germination and plant growth. PAW could potentially be used to increase crop yield and to fight against the drought stress environmental conditions.

Plasma activated water (PAW) obtained from treating water with non thermal atmospheric pressure plasma in air, increases the rate of germination and subsequent plant growth. The aim is to achieve a cheap and eco- friendly production process reducing the wide current use of energy, irrigation water, chemicals and pesticides.

Generating the Plasma-Liquid Water Interaction- As mentioned earlier, lightning discharges through the interaction of liquid water accelerates the reaction inside the liquid. This is caused by the diffusion in the liquid, which reduces the types of gases and is transmitted by the lightning fluid. E.g., nuclear electron attack particles bring about de- associations, but, direct atom-electron connection to water causes atom distortion. Several release methods are possible. Lightning is created on top of the fluid as a category communication fluid. This process can basically be done in several ways: (i) gleam release; (ii) dielectric obstruction release (DBD); and (iii) the coasting curve release. In gleam release electrolysis, the release is initiated between the liquid floor and the external cathode. Depending on the current flow, radical reactions take up radical creation by extending the fluid and fuel portion. In the form of a dielectric boundary, plasma is created near the liquid floor board. Therefore, the reactive species distributed in the fuel phase can be connected to the liquid in the ground by influencing the reaction of water. The Coastal Circular Segment Release works by keeping a quick look at the beam release between the different anodes, followed by adjustment and upward movement. Generally, halls are defined. This release has only recently evolved into a long journey to isolate the cathode everywhere. Due to low lightning discharge, there is no fertilizer and warmth to release. Liquid water is delivered with a framing splash. Flotsam and jetsam, created in the circular section, communicate with water, destroying the natural pollutants present in it. Circular section releases have proven to be a very effective way to treat contaminants in liquid water.

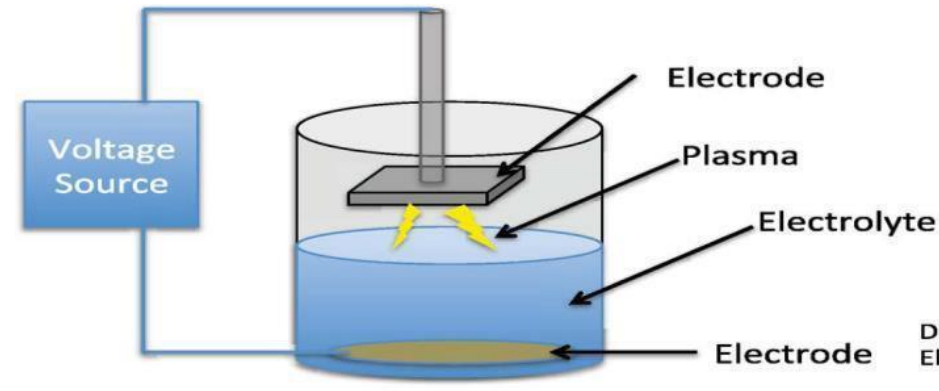

Glow Discharge Electrolysis

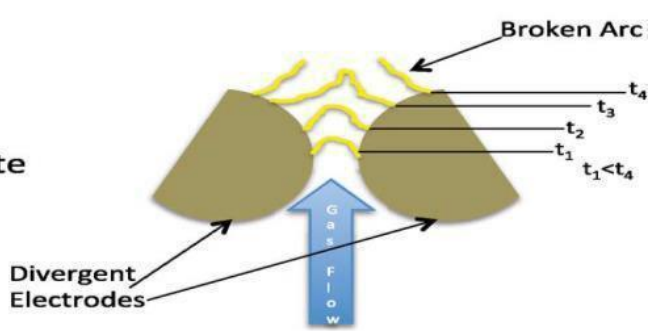

Gliding Arc Discharge

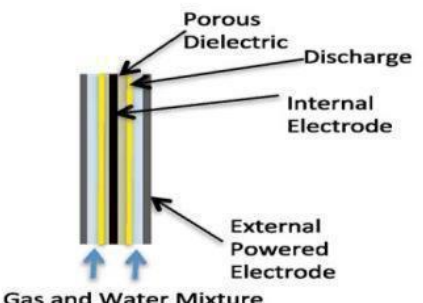

Gas and Water Mixture

Dielectric Barrier Discharge

Fig 3- Surface-water plasma interaction approaches.

Another method of transferring lightning injection to liquid is the intended cheap infusion system, to use a fast and unnecessary voltage beat across the lower terminals. The voltage is an infinite distribution of the beat, and the evidence shows that this is a questionable increase for the neighboring anode. Signs are amplified by liquid-air interaction, which demands the release of developmental decoration release. This time the decorative air extends inside the pocket and increases the hops from the air pocket. In both cases, the release company inside the air pocket. Radicals are designed in the air pocket and in the water / fuel interface. Gurgling provides the science of fluctuations and resulting plasma in the fuel mixture. Energy-regulated signals are concentrated on sharp terminals limited to air pocket development and subsequent fall. The run of the mill part into the plane geometry with and without gurgling. These barometric weight releases a decorative push that produces many radicals that overflow. Therefore, the release of a brief spawn decoration, which regularly controls the amount of heat to nanoseconds, high flotsam, jetsam and liquid media, basically ensures a warm, efficient release. Methods for locking provide a complete evaluation of submerged release strategies. Examining the overall effectiveness of different release strategies is complete.

Blue Eyes Intelligence Engineering

\& Sciences Publication

(C) Copyright: All rights reserved.

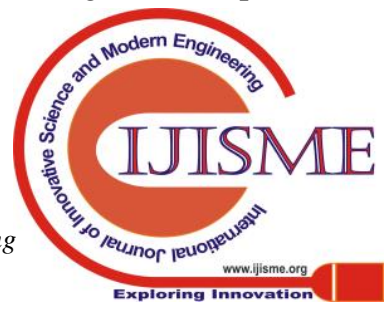


These tests suggest that methods such as adding plasma above liquid water may be beneficial. Regardless, the investigation of lightning inside the fluid has a complex fluid healing mechanism and may limit the risks of water intake. All things considered, additional testing is needed before this mechanical ability can develop into a novelty. Research shows work in the area of connective separation, which is required in demonstration and building exercises.

The previously mentioned method can be incorporated into general fluid cleansing frameworks for pre-purification and inadequate healing processes - as well as for factor-ofutilization programs. By factor-of-utilization, we talk about ready-to-use water purification frameworks. It should break away from integrated and routine water treatment systems. The use of a component, including plasma-based holistic strategies, is particularly appropriate in mature countries or in remote areas where the purification base is not certain. There is no doubt that one billion people need regular drinking water. So $80 \%$ of young people who die are suffering from water damage. The situation is even more important in immature areas, where the legal business loses harmful chemicals or agricultural spillovers - both of which cause water to be tainted. Plasma is basically ready-to-use periodically ready to tackle this cultural crisis. The age of use in commercial settings applies immediately, for example, it is important to take care of the material flowing plants without delaying for a moment before being removed from the waterway or stream.

Plasma based Water Reactor- As mentioned earlier, plasma based water purification techniques have been demonstrated for better performance than traditional advanced oxidation methods for small Treatment volumes. The main problem is throughput and treatment volume.

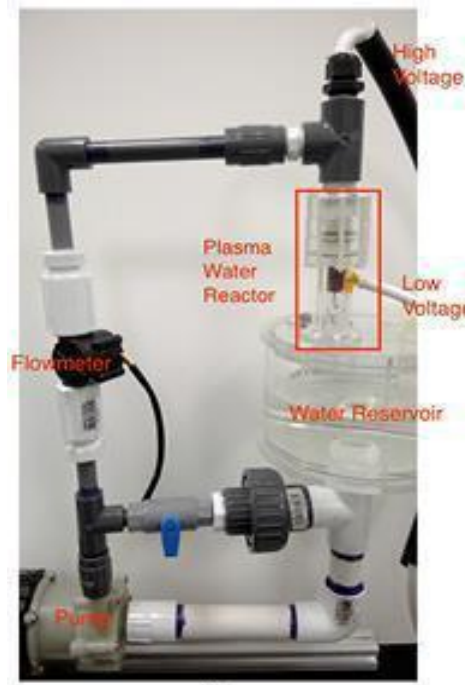

(A)

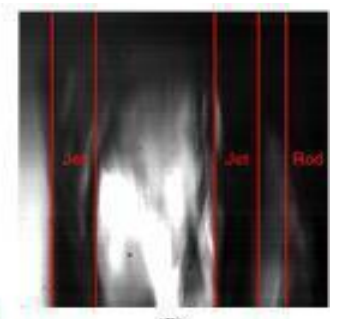

(B)

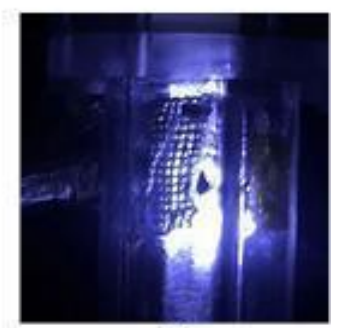

(C)
Fig 4- Plasma based water Reactor

Despite the scale-up challenges, most recently Plasma Purifier Programs are started on a project as an attempt to commercialize plasma Water reactors. Usually, later Laboratory performance, next Steps towards commercialization performance of the policy related to weather regulations this is called piloting. The operation of the policy involves reactor of a water treatment plant as direct wastewater is used for treatment. One piloting demonstration was carried out which is Aquapure. The Aquapure reactor design is faithful where a thin layer of wastewater effluent is subjected to a surface barrier discharge. Water flows under the plasma discharge assemblies in conveyer belt-like fashion. Reactive oxygen species are produced both in the gas phase and at the liquid-plasma interface.

Case study related to Plasma and Liquid water purification- Plasma has ability to perform AOPs as needed from a water purification perspective. Because of this ability, several investigations have shown Includes plasma based water treatment, the decomposition of organic compounds - major pollutants in source water of special interest, Plasma's ability to treat water contaminated with herbicides / Pesticides, VOCs, Bacteria and Textiles, these contaminants are representative of a portion of emerging threats to source waters.

Pesticides - Over 15 million pesticides are used each year. In this case, adding soil resources by blocking the final product. Contamination with aquaculture is also noteworthy which are pathways to the life of pesticides in the liquid, especially to civilization and agriculture. Bug sprays can have many cultural benefits with the sign of crawling disease, crop production and nearby solid particles. The pesticide barrier to groundwater and the groundwater source is in serious danger. By examining the range of solid particles and constructs the controls. Pesticides are refractory; Environmental factors do not break them down without problems. These alloys are natural in this way. The plasma-based method provides the ability to withstand the salinity of such contaminants. Pentachlorophenol (PCP) is the most common carcinogenic compound.

Decontamination- Regular cleaning of the water strainer purifies the flexible fluid and the framework does not address every microbe. For example, as previously demonstrated, chlorine safe microbial spores and protozoa are not conventional. Ongoing oxidation processes break down those pollutants and in that case, such methods can be used in conjunction with ritual systems. Here we are blessed with special cases describing the interaction of lightning in liquid intent using activation with micro-organisms. The beetle crown was released to clean E. coli-microscopic organisms in running water. Resolved test and unfiltered fluid at the entire terminal of the cathode. The cathode is hit with a larger "plane" anode compared to the high voltage. In this test, a 49 Hertz fifty-six $\mathrm{kV}$ beat was inserted into the terminal of the cathode. Technique, the manipulation of the tainted fluid becomes the controlled terminal of the cathode, which is directly coupled with the release of the beat crown. Exponential decrease in state framing gadgets was recorded as part of $98.9 \%$ passive release beat wide acquisition and treatment time. The watch, which has a ready DC plasma stream, has detected high levels of microbial inactivation.

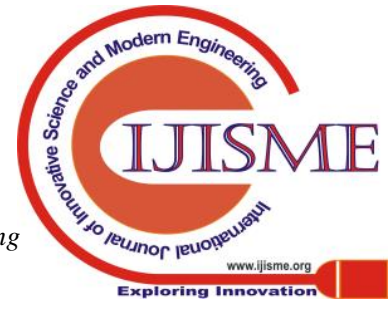


1. Fabric mill Contaminants- Approximately 21\% of the commercial liquid contamination structure is estimated from factory drainage water. It stores about 11 million kilograms of water. Protective texture drainage are the general experience of water shape between photosynthesis strategies of aquatic vegetation. Some of the colors are cancer-causing or carcinogenic, and microbial techniques are used and are therefore fundamental to those who support chain disease. Color elements are detrimental to fish and other lifestyles of the ocean. Because organisms need oxygen to use colored molecules, the proximity of color in water expands the natural oxygen coil, creating areas where there is no oxygen along these lines - passive areas. Fixations and color drainage water are not constantly used. The contamination of the decor factory is confused with the guide of reality that there are more than 100000 specific types of colors. Also, those colors are meant to combat opacity and degradation. Traditional water treatment systems cannot remove such colors. Conventional strategies, including sorption, produce strong sludge - which requires removal or bio-degradation. Forward oxidation strategies in the whole brine of natural dyes show exceptional certainty. With current oxidation strategies, the entire spectrum of colors from water played becomes a real possibility in terms of plant reuse of spent fountains. In some studies, plasma is basically a common color degradation in controlling air pressure and releasing warm and warm. In many experiments on the interaction of plasma with liquid water outlets, the classification of color settings has been found to be a detailed lightning-activated mechanism. Drowned DBD has demonstrated its strategic capabilities strategically. The release device consists of a midway controlled cathode; the flow loop stops the dielectric tube that operates the anode. In this way, the discharge tube is with air conditioning or appropriate voltage beats. When energized with a very low heart rate, the foundation combines discharges with crown lightning and embellishments. Replace lightning with a liquid such as ozone, the radicals created in the cylinder commit to expand the color. Tuberculosis has been demonstrated by using high pressure liquid chromatography spectrophotometric methods.

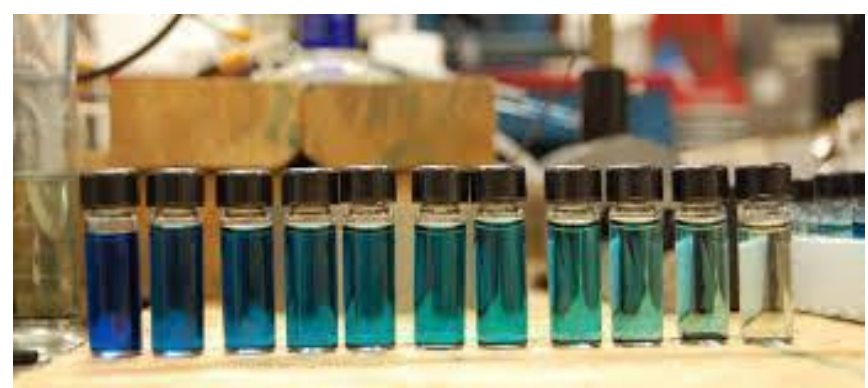

Fig 5- Plasma Treated water sample of Textile Dyes

Plasma in Bubble Mechanism- Almost all plasma injection techniques have been investigated Consisting of electrodes fitted on or below the liquid water. The presence of electrodes in water increases pollution potential due to electrode erosion. Such a deduction, limits the applicant's life span. To achieve necessary electric field breakdown, the inter-electrode spacing must be minimize, which means the process volume is inherent small. An alternative approach that can improve volume processing rates and electrode erosion and then remove discharge product in liquid pollution free bubbles is isolated from the electrode. Plasma formation in free bubbles is suitable for volume processing. Such an approach is necessary for adding enough to the applied field bubble. Inclusion Processing and bubbles should be multiplied. In those cases, the discharge seed can be provided in adjacent bubbles by discharge photoionization. Hence the streamer hopping allows greater volume processing efficiency.

\section{IV.RESULT}

A feasibility study was carried out on water sample collected from water supply and report is being prepared on the basis of test results. It can be seen from the test results that this plasma based water treatment technique is more efficient and cheaper than the current wastewater treatment system. In these experiments $\mathrm{pH}$ was maintained so that after plasma treatment water is safe and potable.

Table 1- Result of Tap water Before and After Plasma Treatment

\begin{tabular}{|l|l|l|l|l|}
\hline Physical and & Tap Water & Tap Water & $\begin{array}{l}\text { IS:10500- } \\
\text { 2012 }\end{array}$ & $\begin{array}{l}\text { IS:10500- } \\
\text { 2012 }\end{array}$ \\
\hline chemical & $\begin{array}{l}\text { Before } \\
\text { Plasma }\end{array}$ & $\begin{array}{l}\text { After } \\
\text { Plasma }\end{array}$ & Acceptable & Permissable \\
\hline parameters & Discharge & Discharge & limits & limit \\
\hline Color & $\begin{array}{l}\text { Colourless } \\
\text { and }\end{array}$ & $\begin{array}{l}\text { Colourless } \\
\text { and }\end{array}$ & Agreeable & Agreeable \\
\hline & Clear & Clear & & \\
\hline Odour & NIL & NIL & & 10 \\
\hline Turbidity & 0.12 & 0.12 & 1 & 2000 \\
\hline TDS (mg/l) & 1020 & 460 & 500 & 200 \\
\hline $\begin{array}{l}\text { Calcium } \\
\text { (mg/l) }\end{array}$ & 106 & 35 & 75 & 100 \\
\hline Magnesium & 51 & 17 & 30 & \\
\hline
\end{tabular}




\begin{tabular}{|l|r|r|r|r|}
\hline (mg/l) & & & & \\
\hline Total & 495 & 132 & 200 & 600 \\
\hline Hardness(as & 230 & 126 & 250 & 1000 \\
\hline $\begin{array}{l}\text { CaCo3) } \\
\text { (mg/l) }\end{array}$ & 0.039 & 0.039 & - & \\
\hline $\begin{array}{l}\text { Chlorides } \\
\text { (mg/l) }\end{array}$ & 7.1 & 6.6 & 6.5 to 8.5 & 6.5 to 8.5 \\
\hline $\begin{array}{l}\text { Nitrogen } \\
\text { (mg/l) }\end{array}$ & 0.11 & 0.11 & 1 & 1.5 \\
\hline pH & & & & \\
\hline $\begin{array}{l}\text { Fluorides } \\
(\mathrm{mg} / \mathrm{l})\end{array}$ & & & & \\
\hline
\end{tabular}

Table 2- Result of water and Dye Before and After Plasma Reaction

\begin{tabular}{|c|c|c|c|c|}
\hline $\begin{array}{l}\text { Physical } \\
\text { and }\end{array}$ & $\begin{array}{l}\text { Dye and } \\
\text { Water }\end{array}$ & $\begin{array}{l}\text { Dye and } \\
\text { Water }\end{array}$ & $\begin{array}{l}\text { IS:10500- } \\
2012\end{array}$ & $\begin{array}{l}\text { IS:10500- } \\
2012\end{array}$ \\
\hline chemical & $\begin{array}{l}\text { Before } \\
\text { Plasma }\end{array}$ & $\begin{array}{l}\text { After } \\
\text { Plasma }\end{array}$ & Acceptable & Permissible \\
\hline parameters & Discharge & Discharge & limits & limit \\
\hline \multirow[t]{2}{*}{ Color } & Blue & $\begin{array}{l}\text { Colorless } \\
\text { and }\end{array}$ & Agreeable & Agreeable \\
\hline & & clear & & \\
\hline Odour & Earthy & NIL & & \\
\hline Turbidity & 74 & 1.3 & 1 & 10 \\
\hline TDS (mg/l) & 987 & 987 & 500 & 2000 \\
\hline $\begin{array}{l}\text { Calcium } \\
(\mathrm{mg} / \mathrm{l})\end{array}$ & 96 & 97 & 75 & 200 \\
\hline Magnesium & 40 & 65 & 30 & 100 \\
\hline \multicolumn{5}{|l|}{$(\mathrm{mg} / \mathrm{l})$} \\
\hline & 390 & 510 & 200 & 600 \\
\hline \multicolumn{5}{|l|}{ Total } \\
\hline \multicolumn{5}{|l|}{ Hardness(as } \\
\hline $\begin{array}{l}\text { CaCo3) } \\
(\mathrm{mg} / \mathrm{l})\end{array}$ & 290 & 210 & 250 & 1000 \\
\hline $\begin{array}{l}\text { Chlorides } \\
(\mathrm{mg} / \mathrm{l})\end{array}$ & 0.09 & 0.035 & - & - \\
\hline $\begin{array}{l}\text { Nitrogen } \\
(\mathrm{mg} / \mathrm{l})\end{array}$ & 8.2 & 7.3 & to $8.5^{6.5}$ & to $8.5^{6.5}$ \\
\hline $\mathrm{pH}$ & 0.1 & 0.1 & 1 & 1.5 \\
\hline $\begin{array}{l}\text { Fluorides } \\
(\mathrm{mg} / \mathrm{l})\end{array}$ & & & & \\
\hline
\end{tabular}




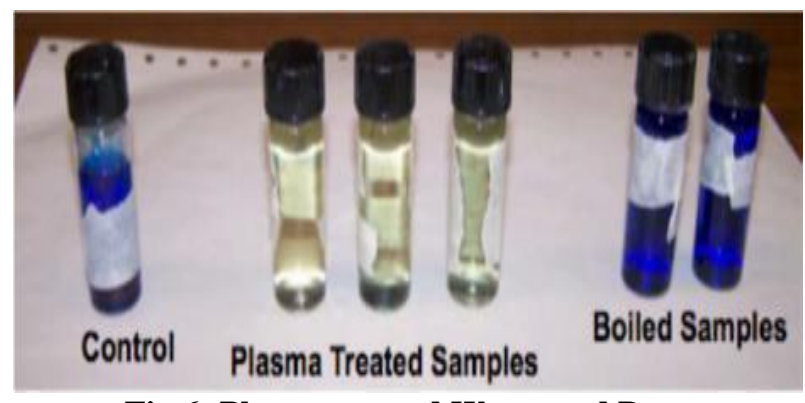

Fig 6- Plasma treated Water and Dye

\section{V.CONCLUSION}

As mentioned, wastewater must be purified to ensure human safety as well as environment. Due to the high cost and maintenance of traditional processing plants, it is difficult for people to properly treat wastewater.

Finally, the ideal state is to promise with new, cost effective, efficient, and innovative concept for wastewater plants i.e. using plasma purification technique that can separate some biological / volatile components and remove from the water, and then removal of biodegradable organic matter.

The technique of lightning connections in the liquid increase rapidly. As lightning describes the method of transporting uniform oxidation strategies in liquids (water). Method for treating fluid intake as a mechanically errant drainage water treatment. This is the era of sparkling liquid cleanser and guaranteed breakthrough factor-consuming liquid preservation capability which ensures immature areas in a unified custom liquid preservation machine. In many respects it has a tendency towards cultural interests. Rich material science extends into the water-air interface. These findings require progress, and the physics and scientific capabilities of lightning that occur there are easy to understand. High composite tests for fluidity, advanced techniques for imaging submerged discharges, and electrochemical tests similar to Langmuir tests are high check lightning bubbles in the interface. Numerous nontheoretical executions have now been discovered, such as set-up, conversion efficiency, device lifetime, and prepared liquid toxicity. Because of lightning, the previously mentioned mechanisms are mainly characterized by asymmetric oxidation mechanisms, such as controlled plasma infusion or transactions. Such a limitation is naturally limited by the throughput and strategic time stand elements. Here, the goal

of improved oxidation mechanisms is to convert pollutants into biodegradable adaptations. This methodology engages from an economic perspective and separates the soul from the price. At the same time, in such an implementation, organic fragment retailers must ensure that the lightning created is not toxic. In a broader sense, independent plasma-based strategies, in contrast to standard dominant oxidation strategies, involve more than one type of oxidation produced during this time, followed by a reduction in treatment time and driving oxidation.

\section{REFERENCES}

1. UN General Assembly Resolution Number GA/10967.Grand Challenges for Engineering, Nat. Acad. Eng., 2008.
2. TheHistoryofDrinkingWaterTreatment, Feb.2000.EPA-816-F-00-006 J. S. Zogorski, J. M. Carter, T. Ivahnenko, W. W. Lapham, M. J. Moran, B. L. Rowe, P. J.

3. Squillace, and P. L. Toccalino, - Volatile organic compounds in the nation's ground water and drinking water supply wells, $\|$ U.S. Geological Survey, Reston, VA, U.S. Geological Survey Rep.

4. Circular 1292, 2006.

5. Organic compounds Assessed in Chattahoochee River Water Used for Public Supply near Atlanta, Georgia, 2004-05, U.S. Geological Survey, Fact Sheet 2011-3062, Jun. 2011.

6. T. Tisler and J. Zagorc-Kocan, -The whole-effluent" toxicity approach,\| Int. J. Environ. Pollution, vol. 31, pp. 3-12, Nov. 2007.

7. O. T. Love, R. J. Miltner, R.G. Eilers, and C.A. Frank-Leist, - Treatment of Volatile Organic Compounds in Drinking Water, EPA-600/8-83-019, May 1983.

8. Drinking Water Contaminants.[Online].Available: http://water.epa.gov/ drink/contaminants/\#organics.

9. S. Suarez, M. Carballa, F. Omil, and J. M. Lema, - How are pharmaceutical and personal care products (PPCPs) removed from urban waste waters, $\|$ Rev. Environ. Sci. Biotechnol., vol.7, pp. 125 128, 2008.

10. P. C. Vandeivere, R. Bianchi, and W. Verstraete, - Treatment and reuse of

drain waterfromthetextilewetprocessingindustry:Reviewofemerging technologies,\| J. Chem. Technol. Biotechnol., vol. 72, no. 4, pp. 289302, Aug. 1998.

11. E. Klimiuk, K. Kabardo, Z. Gusiatin, and U. Filipkowska, -The adsorption of reactive dyes from mixtures containing surfactants onto chitin,\| Polish J. Environ. Studies, vol. 14, no. 6, pp. 771-780, 2005.

12. Y. C. Wong, Y. S. Szeto, W. H. Cheung, and G. McKay, -Pseudofirstorder kinetic studies of the sorption of acid dyes onto chitosan, $\| \mathrm{J}$. Appl. Polym. Sci., vol. 92, no. 3, pp. 1633-1645, May 2004.

13. [13]. V. K. Garg, M. Amita, R. Kumar, and R. Gupta, -Basic dye (methylene blue) removal from simulated drain water by adsorption using Indian Rosewood sawdust: A timber industry waste, $\|$ Dyes Pigments, vol. 63, no. 3, pp. 243-250, Dec. 2004.

14. T.Robinson,G.McMullan,R.Marchant,andP.Nigam,--Remediationof dyes in textile effluent: A critical review on current treatment technologies with a proposed alternative,॥ Bioresource Technol., vol. 77, no. 3, pp. 247-255, May 2001.

15. A. Al-Kdasi, A. Idris, K. Saed, and C. T. Guan, -Treatment of textile drain water by advanced oxidation processes-A review,॥ GLOBAL NEST, Int. J., vol. 6, no. 3, pp. 222-230, Nov. 2004.

16. W. H. Glaze, J.-W. Kang, and D. H. Chaplin, - The chemistry of water treatment processes involving ozone, hydrogen peroxide and ultraviolet radiation,॥ Ozone Sci. Eng., vol. 9, no. 4, pp.335-352, 1987.

17. R. Munter, -Advanced oxidation processes-Current status and prospects,\| Proc. Estonian Acad. Sci. Chem., vol. 50, no. 2, pp. 59-80, Jun. 2001

18. J. H. Carey, - An introduction to AOP for destruction of organics in drain water,\| Water Poll. Res. J. Can., vol. 27, no. 1, pp. 1-21, 1992.

19. J. J. Pignatello, E. Oliveros, and A. MacKay, - Advanced oxidation processes for organic contaminant destruction based on the Fenton reaction and related chemistry, $\|$ Critical Rev.Environ. Sci. Technol. vol. 36, no. 1, pp. 1-84, Jan./Feb. 2006.

20. I. Oller, S. Malato, and J. A. Sanchez-Perez, -Combination of Advanced Oxidation Processes and biological treatments for drain water decontamination-A review,\| Sci. Total Environ., vol. 409, pp. 4141-4146, 2009

21. M. Mohajerani, M. Mehrvar, and F. Ein-Mozaffari, - An overview of the integration of advanced oxidation technologies and other processes for water and drain water treatment, $\|$ Int. J.Eng., vol. 3, no. 2, pp. 120-146, 2009.

22. C. Comninellis, A. Kapalka, S. Malato, S. A. Parsons, I. Poulios, and D. Mantzavinos,-Advanced oxidation processes for water treatment: advances and trends for R\&D,\| J. Chem.Technol. Biotechnol., vol. 83 , no. 6, pp. 769-776, Jun. 2008.

23. John Foster, Bradley S. Sommers, Sarah Nowak Gucker, Isaiah M. Blankson, and Grigory Adamovsky - Perspectives on the Interaction of Plasmas With Liquid Water for Water Purification, IEEE Transaction on plasma science, vol. 40, no. 5, May 2012

24. Dr. Megala. "Drinking Water Activated By Plasma." International Journal of Engineering Research And Development, vol. 16(6), 2020, pp 01-09.

Published By:

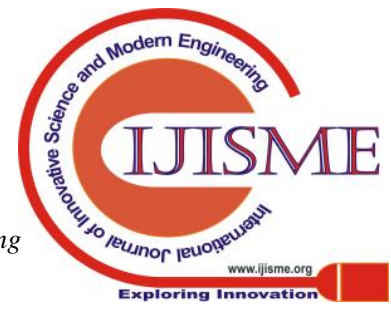




\section{AUTHOR'S PROFILE}

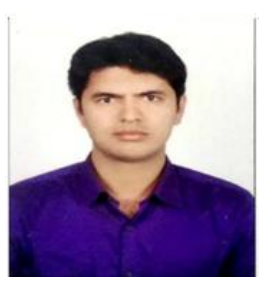

Chandan Kumar, He received his bachelor degree in civil engineering and a master's degree in Structural engineering, granted by B.I.T Sindri in 2014. he received senior research fellowship from CSIR New Delhi during 2015 to 2018. He is currently working as assistant professor, Dept of civil engineering, NSIT Bihta, Patna (India). His research interest includes ageing effect of concrete, soil structure interaction, composite materials, waste water purification using nano-materials, utilization of waste material in concrete, structural dynamic study in different zone of india.

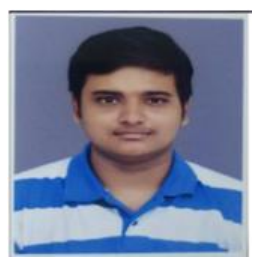

Ankit Raj Sinha, He is pursuing Bachelor's degree in Civil Engineering from NSIT, Bihta Patna during academic year 2016-2020, Aryabhatta Knowledge University, Bihar. He is currently working on "Plasma based waste water Purification", "Ground water Recharge in Patna Region", and on "GFRP use in Concrete Technology" as Research project.

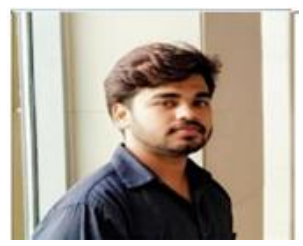

Sanjay Prakash, He is pursuing Bachelor's degree in Civil Engineering from NSIT, Bihta Patna during academic year 2016-2020, Aryabhatta Knowledge University, Bihar. He is currently working on "Plasma based waste water Purification", "Ground water Recharge in Patna Region", and on "GFRP use in Concrete Technology" as Research project

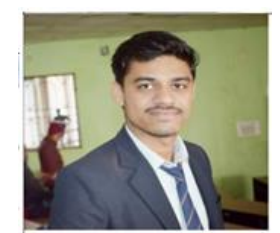

Khushwant Singh, $\mathrm{He}$ is pursuing Bachelor's degree in Civil Engineering from NSIT, Bihta Patna during academic year 2016-2020, Aryabhatta Knowledge University, Bihar. He is currently working on "Plasma based waste water Purification", "Ground water Recharge in Patna Region", and on "GFRP use in Concrete Technology" as Research project.

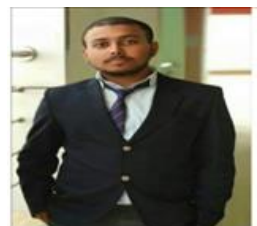

Saurabh Kumar, He is pursuing Bachelor's degree in Civil Engineering from NSIT, Bihta Patna during academic year 2016-2020, Aryabhatta Knowledge University, Bihar. He is currently working on "Plasma based waste water Purification", "Ground water Recharge in Patna Region", and on "GFRP use in Concrete Technology" as Research project.

Published By:

Blue Eyes Intelligence Engineering

$\&$ Sciences Publication

(C) Copyright: All rights reserved. 